\title{
Dynamic reciprocal relationships between cognitive and functional declines along the Alzheimer's disease continuum in the prospective COGICARE study
}

Sophie Carles ${ }^{1}$, Bachirou O. Taddé2, Claudine Berr ${ }^{1}$, Catherine Helmer², Hélène Jacqmin-Gadda², Isabelle Carrière ${ }^{1}$ and Cécile Proust-Lima ${ }^{2^{*}}$ (D)

\begin{abstract}
Background: Thoroughly understanding the temporal associations between cognitive and functional dimensions along the dementia process is fundamental to define preventive measures likely to delay the disease's onset. This work aimed to finely describe the trajectories of cognitive and functional declines, and assess their dynamic bidirectional relationships among subjects at different stages of the dementia process.

Methods: We leveraged extensive repeated data of cognition and functional dependency from the French prospective COGICARE study, designed to better characterize the natural history of cognitive and functional declines around dementia diagnosis. Cognition was measured by the Mini-Mental State Examination, the Isaacs Set Test for verbal fluency, the Benton Visual Retention Test for visuo-spatial memory, and Trail Making Test Part B for executive functioning. Functional dependency was measured by basic and instrumental activities of daily living. The study included 102 cognitively normal, 123 mildly cognitively impaired, and 72 dementia cases with a median of 5 repeated visits over up to 57 months. We used a dynamic causal model which addresses the two essential issues in temporal associations assessment: focusing on intra-individual change and accounting for time.

Results: Better cognitive abilities were associated with lower subsequent decline of the functional level among the three clinical stages with an intensification over time but no reciprocity of the association whatever the clinical status.

Conclusion: This work confirms that the progressive functional dependency could be induced by cognitive impairment. Subjects identified as early as possible with clinically significant cognitive impairments could benefit from preventive measures before the deterioration of activities of daily living and the appearance of dementia clinical signs.
\end{abstract}

Keywords: Activities of daily living, Cognitive aging, Mini-Mental State Examination, Temporal association, Causality, Dementia

\footnotetext{
* Correspondence: cecile.proust-lima@inserm.fr

¿Univ. Bordeaux, INSERM, BPH, U1219, F-33000 Bordeaux, France

Full list of author information is available at the end of the article
}

(c) The Author(s). 2021 Open Access This article is licensed under a Creative Commons Attribution 4.0 International License, which permits use, sharing, adaptation, distribution and reproduction in any medium or format, as long as you give appropriate credit to the original author(s) and the source, provide a link to the Creative Commons licence, and indicate if changes were made. The images or other third party material in this article are included in the article's Creative Commons licence, unless indicated otherwise in a credit line to the material. If material is not included in the article's Creative Commons licence and your intended use is not permitted by statutory regulation or exceeds the permitted use, you will need to obtain permission directly from the copyright holder. To view a copy of this licence, visit http://creativecommons.org/licenses/by/4.0/ The Creative Commons Public Domain Dedication waiver (http://creativecommons.org/publicdomain/zero/1.0/) applies to the data made available in this article, unless otherwise stated in a credit line to the data. 


\section{Background}

There is now evidence that the pathophysiological process of Alzheimer's disease (AD) begins decades before the appearance of clinical signs of dementia [1-4]. AD's preclinical stages may constitute a critical window to define and implement early preventive measures likely to delay the disease's onset or magnitudes of symptoms. Thoroughly describing the multiple dimensions, mainly cognitive and functional ones, all along the complex $\mathrm{AD}$ process, is consequently fundamental. However, longitudinal studies in this field were mainly limited to one dimension at a time ignoring the possible interrelationships with others. Yet, investigating how the different dimensions interplay over time at distinct clinical stages could be a key to better understand the $\mathrm{AD}$ pathological cascade and prioritize interventions.

Uncertainties remain in particular on the temporal relationships between cognitive and functional declines. Subjects with initial clinical presentation of $A D$ have been described with cognitive deficits and no evident limitations in activities of daily living (ADL) that seem to appear later in the disease process [5]. Correlation between cognition and function has been shown to increase as $\mathrm{AD}$ patients progressed from preclinical to moderate dementia [6]. Few studies formally assessed the temporal relationships between patterns of cognitive and functional declines and potential differences in their joint evolution along the AD continuum [7-9]. These results suggest that cognitive decline precedes and predicts subsequent functional impairment assessed notably, in mild cognitive impairment (MCI), by the ability to perform ADL. Functional decline has also been suggested as a predictor of both cognitive decline (but only intermittently and not in incident $\mathrm{AD}$ cases) [10] and conversion from MCI to AD [11].

Since longitudinal processes are likely to vary between individuals and to change over time, two major aspects have to be taken into account when investigating temporal relationships [12]. First, time is central and association assessment should be unrelated to the visit schedule. Second, the interest should be in the intraindividual change rather than the inter-individual differences. Indeed, from a causal perspective, the goal is to understand how the system changes as time goes on, and what factors influence the future individual change [13]. By relying on autoregressive and cross-lagged models (ARCL), the rare studies investigating reciprocal temporal dependencies between cognition and functional dimensions over time $[7,9,10]$ did not account for these two major elements [12]. They considered inter-individual differences between successive levels of variables at observed visit times, thus not targeting intraindividual changes, limiting the interpretation to the visit schedule of the study, and possibly inducing spurious associations if sparse [14]. With cognitive and functional dimensions being measured by scores with ceiling/floor effects or unequal interval scaling [15], a third aspect to take into account is the departure from normality which can induce biased estimates if not properly taken into account [16].

In the current study, we aimed to finely describe the trajectories of both cognitive and functional declines, and assess their dynamic bidirectional relationships among subjects with normal aging, $\mathrm{MCI}$ or $\mathrm{AD}$ participating in a French cohort study, the natural history of COGnitive decline, and the need of CARE in the elderly (COGICARE) study. We applied for that a dynamic multivariate causal model [17] that overcomes the major methodological requisites to assess temporal associations.

\section{Methods}

\section{The COGICARE study}

The current study analyses the data from COGICARE which is a sub-study of the Three-City (3C) study in Montpellier and Bordeaux centers. COGICARE was designed to better characterize the natural history of cognitive and functional declines around dementia diagnosis through an extensive follow-up of subjects at three different stages: $\mathrm{AD}, \mathrm{MCI}$, or cognitively normal $(\mathrm{CN})$. The study protocols of the $3 \mathrm{C}$ and COGICARE studies were approved by the Ethics Committee of the University Hospital of Bicêtre and Sud-Méditerranée III (France) and written informed consent was obtained for each participant.

The 3C study is a community-living cohort of 9294 elders ( $\geq 65$ years of age) randomly recruited from the electoral rolls of three French cities (Bordeaux, Dijon, and Montpellier) between 1999 and 2001 [18]. Standardized examinations including face-to-face interviews and cognitive and functional assessments (in a medical center or at home) took place at inclusion and then every $2-3$ years (i.e., after 2, 4, 7, 10, 12, and 14 years of follow-up). AD incident cases diagnosis was based on an examination by a neurologist of all participants in Montpellier and of participants suspected of having dementia (based mainly on their clinical, cognitive, or functional assessments) in Bordeaux. An adjudication panel of independent neurologists reviewed all the existing information to confirm the diagnosis of dementia according to the Diagnostic and Statistical Manual of Mental Disorders, 4th edition (DSM-IV) [19], and its etiology. AD was classified according to the National Institute of Neurological and Communicative Disorders and Stroke and the Alzheimer's Disease and Related Disorders Association (NINCDS/ADRDA) criteria [20]. MCI was defined as (details in Web appendix 1) (i) an alteration of verbal episodic memory (i.e., a free recall score $<17$ and a total recall score $<40)$ [21] on the Free and Cued 
Selective Reminding Test (FCSRT) [22] and (ii) partial or total limitation in their abilities to perform at least two of four Instrumental Activities of Daily Living (IADL) [23].

The following were eligible to enter the COGICARE sub-study: (1) AD incident cases from Bordeaux and Montpellier centers diagnosed at the 3C 7- or 9-year follow-up and non-demented at the last visit preceding the $\mathrm{AD}$ diagnosis. Each incident $\mathrm{AD}$ case was theoretically matched to one control considered as cognitively normal $(\mathrm{CN})$ from the pool of participants free of both dementia and $\mathrm{MCI}$ according to sex, age $(+/-2.5$ years), and examination date (within the interval of 45 days before or after the diagnosis date of their matched $A D$ case); (2) participants who fulfilled criteria for MCI at the 3C 9-year follow-up.

Of the 4363 participants included in the Bordeaux's and Montpellier's centers, 2751 and 2409 were still followed at the 3C 7- and 9-year follow-up, respectively. Among all incident AD cases at the 7- $(n=133)$ and 9year $(n=114)$ follow-up, 176 were included in COGICARE (participation rate: $71 \%$ ). Furthermore, $166 \mathrm{MCI}$ identified at the 3C 9-year follow-up were included. A total of 125 matched $\mathrm{CN}$ controls were included. The 467 COGICARE participants (AD, MCI, or CN), underwent cognitive and functional assessments every 6 months from the $3 \mathrm{C}$ 9-year follow-up (thereafter considered as baseline) and during 18-24 months and then underwent their planned $3 \mathrm{C}$ follow-ups.

\section{Cognitive and functional assessments}

Three cognitive tests were intensively administered during COGICARE follow-up. The global cognitive function was assessed using the face-to-face 30-item MiniMental-State-Examination (MMSE) [24] for AD and $\mathrm{MCI}$, and the telephonic 25-item MMSE for CN. Telephonic 25-item MMSE scores were rescaled so that all MMSE scores ranged from 0 (severe impairment) to 30 (no impairment). The verbal fluency was assessed by the Isaacs Set Test (IST) truncated at 30 s [25] which was either administered face-to-face for $\mathrm{AD}$ and $\mathrm{MCI}$ or by telephone for the $\mathrm{CN}$. Its range was 0 to 82 . The visuospatial memory was assessed by the Benton Visual Retention Test (BVRT) [26] (range 0-15) during face-toface interviews for $\mathrm{AD}$ and $\mathrm{MCI}$. In addition, we considered the Trail Making Test Part B (TMT-B) [27] administered only during the $3 \mathrm{C}$ visits (twice during this study period) in order to include a measure of executive functioning to the cognitive level definition. The score was the number of correct moves per minute.

Functional dependency was assessed by the limitation in basic ADL (BADL) scale [28] and Instrumental ADL (IADL) scale [23] during face-to-face (for $\mathrm{AD}$ and $\mathrm{MCI}$ ) and telephonic interviews (for $\mathrm{CN}$ ). A total of 5 BADL (bathing, dressing, toileting, eating, and transferring) and 4 IADL (telephone use, transportation, self-administration of medication, finances) were considered [29], each one on a 3-point scale as having no limitation, partial limitation, or total limitation (coded 0,1 , and 2 respectively) in performing the task. Following a previous work that showed a continuum in IADL and BADL [30], we considered the total sumscore of IADL and BADL which ranged from 0 to18.

\section{Study sample within COGICARE}

From the 467 participants of the COGICARE study, we excluded the individuals with no repeated cognitive or functional measures during the 57 months of follow-up considered for the present study, and with incomplete information on potential confounders (Flowchart in Web Figure 1). Potential confounders were age at baseline (3C 9-year follow-up) in 5 categories chosen at the quintiles of the distribution $(\leq 79.1$ as the reference class, 79.1-82.0, 82.0-84.5, 84.5-87.7, $\geq 87.7$ ), sex, binary educational level (lower/equal to primary school versus higher than primary school), and Apolipoprotein E (apoE) $\varepsilon 4$ status (at least one $\varepsilon 4$ allele versus none). The final study sample included 297 individuals.

\section{Statistical analysis}

Trajectories of cognitive and functional declines and their temporal reciprocal relationships according to the clinical status (AD, MCI, CN) were assessed using a multivariate latent process model [17]. The theoretical graph of the model is specified in Fig. 1.

The model describes the trajectories and interdependencies over time of the cognitive functioning and functional dependency, defined as two latent processes. Cognitive process was measured by MMSE, IST, BVRT, and TMT-B while functional process was measured by the BADL-IADL sum score. In order to correct for its departure from normality and ceiling/floor effect, each observed marker was linked to its underlying latent process using a marker-specific parameterized link function approximated by quadratic I-splines with two internal knots chosen at the quartiles for the MMSE, IST, BVRT, and TMT-B, and one internal knot at the median for the limitation score [31]. The latent processes were standardized (mean 0 , standard deviation 1 ) at baseline in the reference category ( $\mathrm{CN}$ men with a higher educational level and less than 79.1 years old at baseline). Thus, in the results section, a one-unit change of cognition or functional dependency always corresponds to the residual standard deviation of the dimension at baseline after adjustment for age, sex, age, and clinical stage.

The longitudinal model for the cognitive and functional latent trajectories was split in two subparts to exhibit the temporal relationships. Both parts accounted 


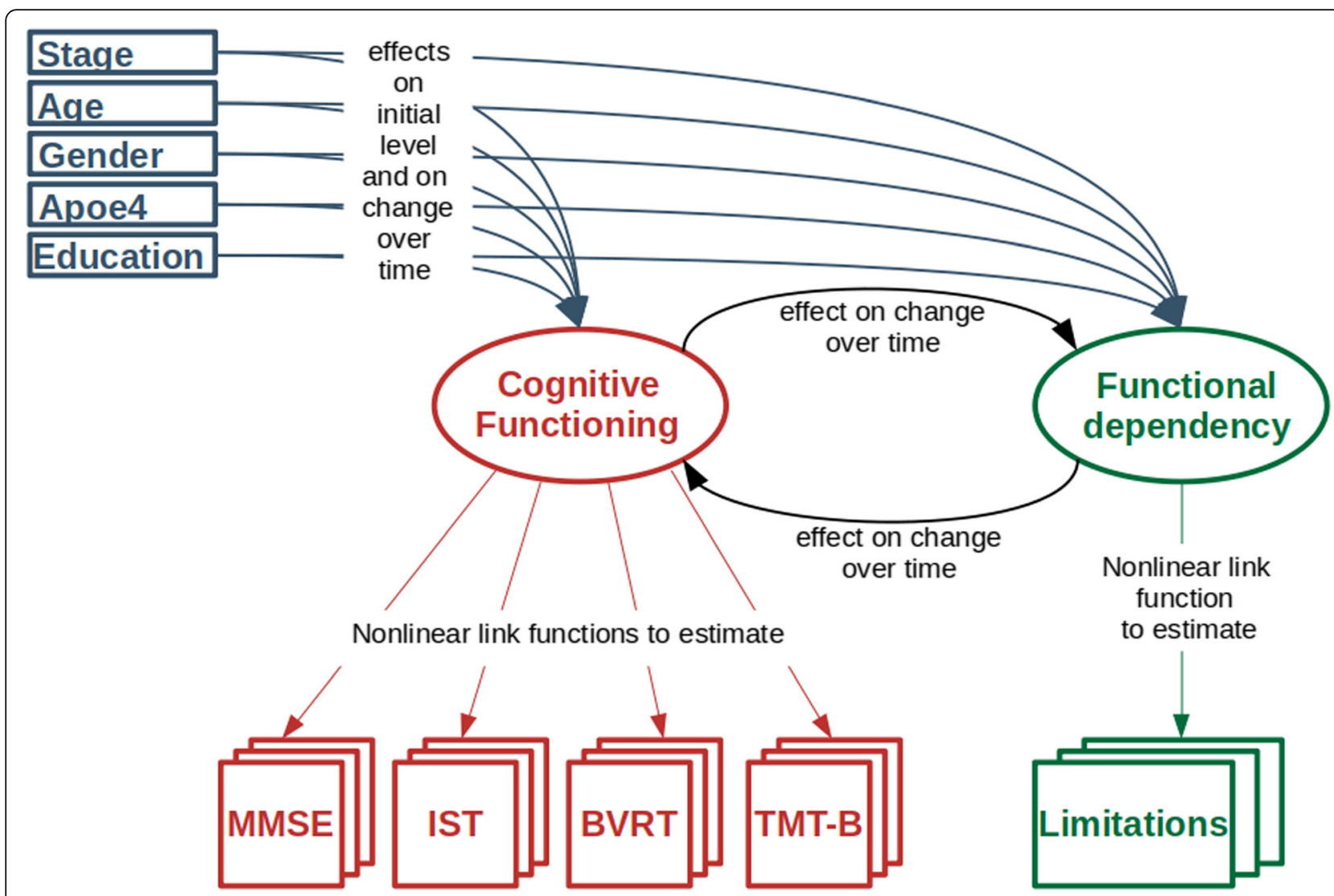

Fig. 1 Theoretical graph of the dynamic causal model

for intra-individual correlation and missing at random mechanism (as based on the mixed model theory [32]):

- The initial levels of cognitive ability and functional dependency were regressed on the stage of the disease, age, apoE4 status, gender, education, the interaction between education and stage, and an individual random intercept.

- The changes over time of cognitive ability and functional dependency were described over a finely discretized time of 3 months unrelated to the visit process. The change between $t$ and $t+3$ months was regressed on the same covariates as initial levels, an individual random effect, and the level of cognitive ability and functional dependency at time $t$. The effect of the level of cognitive ability and functional dependency on each other was different by stage and could vary over time to precisely explore their inter-relations, and especially potential changes in these relationships over time. Further details on the dynamic model specification are given in Web Appendix 2.

Statistical analyses were done with $\mathrm{R}$ software and the dynamic model was fitted using CInLPN $R$ package available at https://github.com/bachirtadde/CInLPN. Reported $P$ values are from two-sided Wald tests.

\section{Results}

\section{Sample description}

The study sample included $102 \mathrm{CN}$ (34.3\%), 123 were MCI (41.4\%), and 72 were AD (24.3\%). AD subjects (median age 84.4 years) were slightly older than MCI (82.0 years) and $\mathrm{CN}$ (83.4 years) at inclusion (Table 1). Two third of the sample were women with slight differences over groups $(65.3 \%, 58.5 \%$, and $67.6 \%$ for $\mathrm{AD}, \mathrm{MCI}$, and $\mathrm{CN}$, respectively). $\mathrm{MCI}$ and $\mathrm{AD}$ subjects had a lower educational level compared to $\mathrm{CN}$. Subjects with $\mathrm{AD}$ were more frequently APOE $\varepsilon 4$ carriers than $\mathrm{CN}(36.1 \%$ vs $14.7 \%)$. The percentage of individuals with no IADL and BADL limitations at baseline gradually decreased between $\mathrm{CN}, \mathrm{MCI}$, and $\mathrm{AD}$, and $\mathrm{MCI}$ and $\mathrm{AD}$ had lower cognitive scores than $\mathrm{CN}$.

The 170 excluded subjects (see flowchart in Web Figure 1) were more likely $\mathrm{AD}(61.2 \% \mathrm{AD}, 13.5 \% \mathrm{MCI}$, $25.3 \% \mathrm{CN}$ ). They were slightly older (median age: 86.5 ) and more likely to be women (72.9\%) than included subjects but comparable regarding their education level and APOE $\varepsilon 4$ status. 
Table 1 Characteristics of participants at baseline $(n=297)$, COGICARE study

\begin{tabular}{|c|c|c|c|c|}
\hline & $\begin{array}{l}\mathrm{CN} \\
(N=102)\end{array}$ & $\begin{array}{l}\mathrm{MCl} \\
(N=123)\end{array}$ & $\begin{array}{l}\mathrm{AD} \\
(N=72)\end{array}$ & $\begin{array}{l}\text { All } \\
(N=297)\end{array}$ \\
\hline Age in years: median (min-max) & $83.4(75.6-92.8)$ & $82.0(74.2-95.2)$ & $84.4(76.0-93.5)$ & $82.9(74.2-95.2)$ \\
\hline Male sex (\%) & 32.35 & 41.46 & 34.72 & 36.70 \\
\hline Education level higher than primary school (\%) & 77.45 & 65.85 & 62.50 & 69.02 \\
\hline ApoE4 carriers (\%) & 14.71 & 13.82 & 36.11 & 19.53 \\
\hline \multicolumn{5}{|l|}{ Limitation in activities of daily living (\%): } \\
\hline \multicolumn{5}{|l|}{ Bathing } \\
\hline No limitation & 96.08 & 95.93 & 66.67 & 88.89 \\
\hline Partial limitation & 1.96 & 2.44 & 16.67 & 5.72 \\
\hline Total limitation & 1.96 & 1.63 & 16.67 & 5.39 \\
\hline \multicolumn{5}{|l|}{ Dressing } \\
\hline No limitation & 96.08 & 97.56 & 73.61 & 91.25 \\
\hline Partial limitation & 0.98 & 1.63 & 13.89 & 4.38 \\
\hline Total Limitation & 2.94 & 0.81 & 12.50 & 4.38 \\
\hline \multicolumn{5}{|l|}{ Toileting } \\
\hline No limitation & 100.00 & 99.19 & 95.83 & 98.65 \\
\hline Partial limitation & 0.00 & 0.00 & 4.17 & 1.01 \\
\hline Total limitation & 0.00 & 0.81 & 0.00 & 0.34 \\
\hline \multicolumn{5}{|l|}{ Transfering } \\
\hline No limitation & 99.02 & 99.19 & 94.44 & 97.98 \\
\hline Partial limitation & 0.98 & 0.81 & 5.56 & 2.02 \\
\hline Total limitation & 0.00 & 0.00 & 0.00 & 0.00 \\
\hline \multicolumn{5}{|l|}{ Eating } \\
\hline No limitation & 99.02 & 100.00 & 95.83 & 98.65 \\
\hline Partial limitation & 0.98 & 0.00 & 4.17 & 1.35 \\
\hline Total limitation & 0.00 & 0.00 & 0.00 & 0.00 \\
\hline \multicolumn{5}{|l|}{ Limitation in instrumental activities of daily living (\%): } \\
\hline \multicolumn{5}{|l|}{ Telephone use } \\
\hline No limitation & 100.00 & 95.12 & 56.94 & 87.54 \\
\hline Partial limitation & 0.00 & 4.88 & 36.11 & 10.77 \\
\hline Total limitation & 0.00 & 0.00 & 6.94 & 1.68 \\
\hline \multicolumn{5}{|l|}{ Shopping } \\
\hline No limitation & 78.43 & 77.24 & 36.11 & 67.68 \\
\hline Partial limitation & 13.73 & 19.51 & 26.39 & 19.19 \\
\hline Total limitation & 7.84 & 3.25 & 37.50 & 13.13 \\
\hline \multicolumn{5}{|l|}{ Transportation } \\
\hline No limitation & 79.41 & 83.74 & 44.44 & 72.73 \\
\hline Partial limitation & 19.61 & 15.45 & 48.61 & 24.92 \\
\hline Total limitation & 0.98 & 0.81 & 6.94 & 2.36 \\
\hline \multicolumn{5}{|l|}{ Medication } \\
\hline No limitation & 99.02 & 95.12 & 48.61 & 85.19 \\
\hline Partial limitation & 0.00 & 4.07 & 25.00 & 7.74 \\
\hline Total limitation & 0.98 & 0.81 & 26.39 & 7.07 \\
\hline
\end{tabular}

Finances 
Table 1 Characteristics of participants at baseline $(n=297)$, COGICARE study (Continued)

\begin{tabular}{|c|c|c|c|c|}
\hline & $\begin{array}{l}\mathrm{CN} \\
(N=102)\end{array}$ & $\begin{array}{l}\mathrm{MCl} \\
(N=123)\end{array}$ & $\begin{array}{l}A D \\
(N=72)\end{array}$ & $\begin{array}{l}\text { All } \\
(N=297)\end{array}$ \\
\hline No limitation & 89.22 & 86.99 & 41.67 & 76.77 \\
\hline Partial limitation & 10.78 & 11.38 & 26.39 & 14.81 \\
\hline Total limitation & 0.00 & 1.63 & 31.94 & 8.42 \\
\hline \multicolumn{5}{|l|}{ Cognitive scores: median (min-max) } \\
\hline MMSE & $28(17-30)$ & $27(20-30)$ & $23(11-28)$ & $27(11-30)$ \\
\hline IST & $45(22-82)$ & 39 20-61) & $29(12-62)$ & $39(12-82)$ \\
\hline BVRT & $12(6-15)$ & $11(5-15)$ & $9(5-14)$ & $11(5-15)$ \\
\hline TMT-B & $26.5(3.0-60.0)$ & $21.3(0.5-62.6)$ & $7.3(0.7-40.0)$ & $20.0(0.5-62.6)$ \\
\hline Limitation score: median (min-max) & $0(0-7)$ & $0(0-14)$ & $3(0-13)$ & $0(0-14)$ \\
\hline \multicolumn{5}{|c|}{ Number of measures by subject over follow-up: median (min-max) } \\
\hline MMSE & $5(2-6)$ & $5(2-7)$ & $4(1-7)$ & $5(1-7)$ \\
\hline IST & $4(1-6)$ & $5(1-7)$ & $4(1-7)$ & $4(1-7)$ \\
\hline BVRT & $2(1-4)$ & $5(2-6)$ & $3(1-7)$ & $3(1-7)$ \\
\hline TMT-B & $2(1-2)$ & $1(1-2)$ & $1(1-2)$ & $1(1-2)$ \\
\hline Limitations & $5(2-6)$ & $5(2-7)$ & $5(2-7)$ & $5(2-7)$ \\
\hline
\end{tabular}

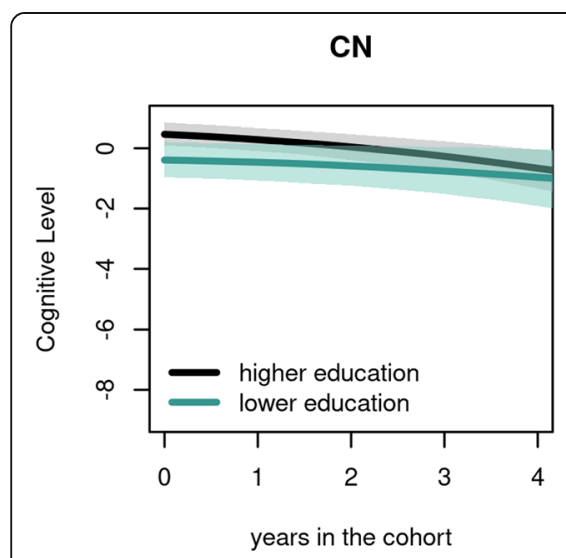

CN

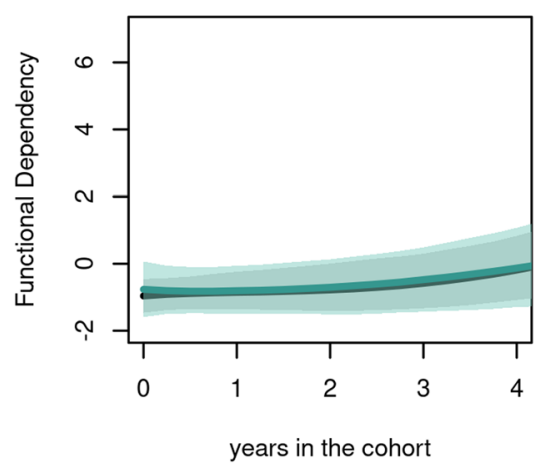

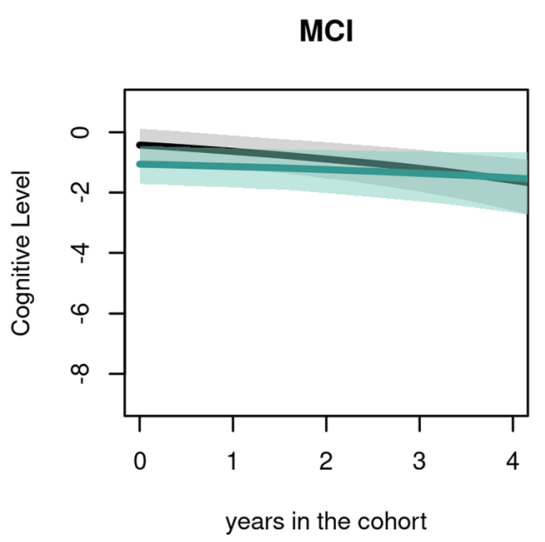

$\mathrm{MCI}$

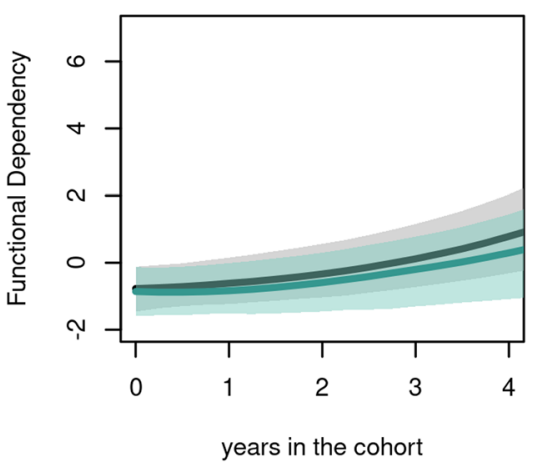

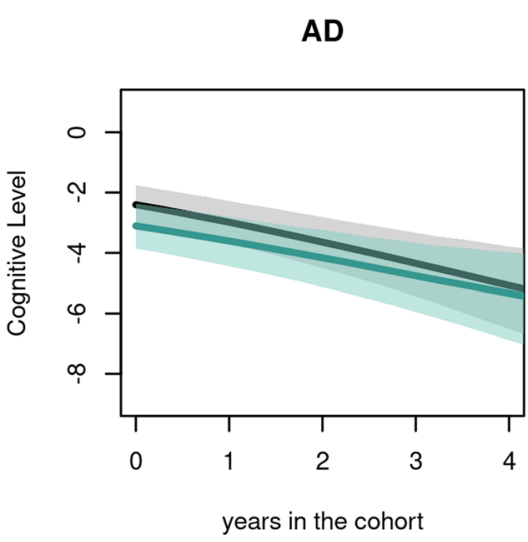

AD

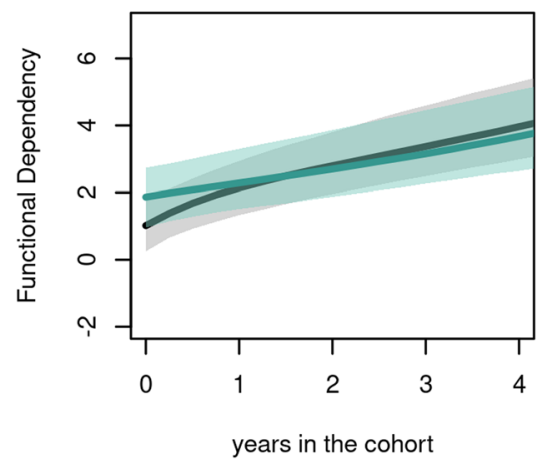

Fig. 2 Predicted mean trajectories over time (plain line) and associated $95 \%$ confidence intervals (shades) of the underlying cognitive ability and functional dependency according to the clinical stage $(\mathrm{CN}, \mathrm{MCl}$, and $\mathrm{AD}$ ) and education; trajectories are displayed for non-APOE $\varepsilon 4$ carriers; male sex and aged between 82.60 and 85.12. Ninety-five percent confidence intervals were obtained using a Monte Carlo method with 2000 draws 
The sample comprised a total of 3974 and 1388 repeated measures of cognition (through the 4 scores) and function, respectively. The median number of visits per participant was 5 for all groups. Web Table 1 and Web Figure 2 further describe the number of measurements available by clinical stage and 3-month steps and the observed individual marker trajectories.

\section{Cognitive and functional trajectories}

The mean predicted trajectories of cognition and function showed a gradual progression from normal to AD stage with differences according to education (Fig. 2). Estimations from the dynamic model for cognitive and functional trajectories are reported in Table 2 for the baseline levels and in Table 3 for the rates of change and further described below. The association between observed markers and the underlying dimensions highlighted the curvilinear nature of the markers and notably confirmed the ceiling effect of MMSE and the floor effect of TMT-B (See Web Figure 3). The adequacy of the model to the data was very good (see Web Figure 4 for the comparison of predictions with observations).

\section{Association with baseline cognitive and functional levels}

A gradient in baseline cognitive and functional abilities was observed according to the clinical stage after adjustment for other potential confounding factors, with slight differences according to education. Participants with an educational level higher than primary school had systematically a higher cognitive level in mean compared to low educated participants with no substantial differences across groups (mean difference in the latent dimension scale $(\mathrm{MD})=-0.868,95 \%$ confidence interval $(95 \% \mathrm{CI})=-1.308,-0.429, P=0.0001$ for $\mathrm{CN} ; \mathrm{MD}=-0.649,95 \% \mathrm{CI}=-1.013,-0.285, P=0.0005$ for MCI; and MD $=-0.695,95 \% \mathrm{CI}=-1.178,-0.211, P=$ 0.005 for $\mathrm{AD}$ ). For functional dependency, differences according to education were only observed among $\mathrm{AD}$ subjects, lower educated $\mathrm{AD}$ subjects having higher limitations than higher educated $\mathrm{AD}$ subjects $(\mathrm{MD}=0.838,95 \% \mathrm{CI}=$ $0.237,1.439, P=0.006$ ). Adjusted for clinical stage and other potential confounding factors, there were no differences in cognition according to APOE $\varepsilon 4$ status $(p=0.954)$ and gen$\operatorname{der}(p=0.903)$. However, APOE $\varepsilon 4$ carriers tended to have a better functional ability $(\mathrm{MD}=-0.355,95 \% \mathrm{CI}=-$

Table 2 Estimated associations with the underlying cognitive ability and functional dependency level at baseline $(n=297)$, COGICARE study

\begin{tabular}{|c|c|c|c|c|c|c|}
\hline \multirow{2}{*}{ Clinical stage by education level } & \multicolumn{3}{|c|}{ Cognitive ability at baseline } & \multicolumn{3}{|c|}{ Functional dependency at baseline } \\
\hline & Coefficient* & \multicolumn{2}{|c|}{ 95\% confidence interval } & Coefficient* & \multicolumn{2}{|c|}{$95 \%$ confidence interval } \\
\hline \multicolumn{7}{|c|}{ Higher than primary school } \\
\hline $\mathrm{CN}$ & 0 & - & & 0 & - & \\
\hline $\mathrm{MCl}$ & -0.882 & -1.284 & -0.480 & 0.171 & -0.275 & 0.617 \\
\hline$A D$ & -2.878 & -3.419 & -2.337 & 1.974 & 1.415 & 2.532 \\
\hline \multicolumn{7}{|c|}{ Lower or equal to primary school } \\
\hline $\mathrm{CN}$ & -0.868 & -1.308 & -0.429 & 0.188 & -0.417 & 0.793 \\
\hline $\mathrm{MCl}$ & -1.531 & -2.044 & -1.018 & 0.089 & -0.412 & 0.591 \\
\hline$A D$ & -3.572 & -4.219 & -2.926 & 2.811 & 2.105 & 3.518 \\
\hline \multicolumn{7}{|c|}{ Age at baseline } \\
\hline$\leq 79.1$ & 0 & - & & 0 & - & \\
\hline $79.1-82.0$ & -0.284 & -0.680 & 0.113 & 0.069 & -0.396 & 0.534 \\
\hline $82.0-84.5$ & -0.461 & -0.870 & -0.053 & 0.304 & -0.167 & 0.775 \\
\hline $84.5-87.7$ & -0.288 & -0.691 & 0.116 & 0.284 & -0.200 & 0.767 \\
\hline$>87.7$ & -0.754 & -1.146 & -0.362 & 1.028 & 0.508 & 1.549 \\
\hline \multicolumn{7}{|c|}{ APOE \&4 carrier } \\
\hline \multicolumn{7}{|l|}{ No } \\
\hline Yes & -0.010 & -0.351 & 0.331 & -0.355 & -0.741 & 0.031 \\
\hline \multicolumn{7}{|l|}{ Sex } \\
\hline \multicolumn{7}{|l|}{ Male } \\
\hline Female & -0.016 & -0.270 & 0.238 & 0.316 & -0.017 & 0.650 \\
\hline
\end{tabular}

*One-unit difference corresponds to the standard deviation of the dimension at baseline in the category reference (CN men with a higher educational level and less than 79.6 years old at baseline) 
Table 3 Estimated associations with the rate of change of underlying cognitive ability and functional dependency ( $n=297)$, COGICARE study

\begin{tabular}{|c|c|c|c|c|c|c|}
\hline \multirow[b]{3}{*}{ Intercept } & \multicolumn{3}{|c|}{ Change over time of cognitive ability } & \multicolumn{3}{|c|}{ Change over time of functional dependency } \\
\hline & \multirow{2}{*}{$\begin{array}{l}\text { Coefficient* } \\
-0.247\end{array}$} & \multicolumn{2}{|l|}{$95 \% \mathrm{Cl}$} & \multirow{2}{*}{$\begin{array}{l}\text { Coefficient* } \\
0.201\end{array}$} & \multicolumn{2}{|l|}{$95 \% \mathrm{Cl}$} \\
\hline & & -0.371 & -0.122 & & -0.370 & 0.772 \\
\hline \multicolumn{7}{|l|}{ Clinical stage } \\
\hline$C N$ & 0 & - & & 0 & - & \\
\hline $\mathrm{MCl}$ & 0.176 & 0.021 & 0.332 & 0.194 & -0.223 & 0.611 \\
\hline$A D$ & 0.377 & -0.031 & 0.785 & 2.166 & 0.784 & 3.549 \\
\hline \multicolumn{7}{|l|}{ Age at baseline } \\
\hline$\leq 79.6$ & 0 & - & & 0 & - & \\
\hline $79.60-82.60$ & -0.021 & -0.165 & 0.124 & -0.144 & -0.552 & 0.264 \\
\hline $82.60-85.12$ & -0.040 & -0.191 & 0.110 & -0.091 & -0.508 & 0.325 \\
\hline $85.12-88.34$ & 0.003 & -0.141 & 0.148 & 0.175 & -0.248 & 0.599 \\
\hline$>88.34$ & 0.043 & -0.119 & 0.204 & 0.732 & 0.114 & 1.349 \\
\hline \multicolumn{7}{|l|}{ APOE \&4 carrier } \\
\hline No & 0 & - & & 0 & - & \\
\hline Yes & -0.017 & -0.139 & 0.104 & -0.211 & -0.582 & 0.159 \\
\hline \multicolumn{7}{|l|}{ Sex } \\
\hline Male & 0 & - & & 0 & - & \\
\hline Female & 0.061 & -0.036 & 0.157 & 0.117 & -0.201 & 0.436 \\
\hline \multicolumn{7}{|l|}{ Education level } \\
\hline > Primary school & 0 & - & & 0 & - & \\
\hline$\leq$ Primary school & 0.239 & 0.124 & 0.355 & -0.471 & -0.828 & -0.114 \\
\hline \multicolumn{7}{|c|}{ Current functional level ${ }^{* *}$} \\
\hline $\mathrm{CN}$ & -0.086 & -0.254 & 0.082 & -1.105 & -1.943 & -0.267 \\
\hline $\mathrm{MCl}$ & -0.010 & -0.141 & 0.122 & -0.643 & -1.247 & -0.038 \\
\hline$A D$ & -0.032 & -0.160 & 0.096 & -0.877 & -1.484 & -0.269 \\
\hline $\mathrm{CN} \times$ time & 0.032 & -0.035 & 0.100 & & & \\
\hline $\mathrm{MCl} \times$ time & -0.008 & -0.057 & 0.042 & & & \\
\hline$A D \times$ time & 0.033 & -0.003 & 0.069 & & & \\
\hline \multicolumn{7}{|c|}{ Current cognitive level ${ }^{* *}$} \\
\hline $\mathrm{CN}$ & 0.154 & 0.052 & 0.255 & -0.403 & -0.783 & -0.023 \\
\hline $\mathrm{MCl}$ & 0.185 & 0.081 & 0.290 & -0.307 & -0.609 & -0.006 \\
\hline$A D$ & 0.235 & 0.130 & 0.340 & --0.342 & -0.601 & --0.083 \\
\hline $\mathrm{CN} \times$ time & & & & -0.281 & -0.468 & -0.095 \\
\hline $\mathrm{MCl} \times$ time & & & & -0.215 & -0.413 & -0.018 \\
\hline$A D \times$ time & & & & -0.043 & -0.099 & 0.014 \\
\hline
\end{tabular}

*One unit corresponds to an annual change of the same size as one standard deviation of the dimension at baseline in the reference category (CN men with a higher educational level and less than 79.6 years old at baseline)

${ }^{* *}$ One unit corresponds to the standard deviation of the dimension at baseline in the reference category (CN men with a higher educational level and less than 79.6 years old at baseline)

0.741,0.0310, $P=0.072$ ) at baseline compared to non-carriers, and so did men $(\mathrm{MD}=-0.316,95 \% \mathrm{CI}$ $=-0.650,0.017, P=0.063)$. Older individuals were more cognitively and functionally impaired adjusted for the other factors.
Association with cognitive and functional rates of change Adjusted for confounding factors, the functional level at any time $t$ was not significantly associated with the subsequent rate of change in cognitive dimension in any group (all $\mathrm{p}>0.320$ ). In contrast, whatever the clinical 
stage, the cognitive level significantly affected the subsequent rate of change of functional dependency after adjustment on potential confounding factors (in all groups: $\mathrm{p}<0.045$ at baseline, $\mathrm{p}<0.009$ at 2 years, $\mathrm{p}<0.012$ at 4 years). As illustrated in Fig. 3, higher cognitive abilities at any given time were systematically associated with a lower subsequent change in functional limitations with an intensification of the association over time for $\mathrm{CN}$ subjects and to a lesser extent for MCI (and even lesser extent for $\mathrm{AD}$ ). This means that the benefit of better cognitive abilities on the change of limitation was larger and larger as the time spent in the cohort increased. The annual change in functional limitations was reduced by $0.403(95 \% \mathrm{CI}=0.023,0.783, P=0.037), 0.966(95 \% \mathrm{CI}=$ $0.355,1.576, P=0.002)$, and $1.529(95 \% \mathrm{CI}=0.591$, 2.466, $P=0.001)$ for a one-unit increase of current cognition in $\mathrm{CN}$ subjects after 0,2 , and 4 years in the cohort, respectively. It was reduced by $0.307(95 \% \mathrm{CI}=$ $0.006,0.609, P=0.045), 0.738(95 \% \mathrm{CI}=0.184,1.293, P$ $=0.009)$, and $1.169(95 \% \mathrm{CI}=0.255,2.084, P=0.012)$ for a one-unit increase of current cognition in MCI subjects after 0,2 , and 4 years, respectively. It was reduced by $0.342(95 \% \mathrm{CI}=0.083,0.601, P=0.010), 0.427(95 \% \mathrm{CI}=$ $0.118,0.736, P=0.007)$, and $0.512(95 \% \mathrm{CI}=0.126,0.899$, $P=0.009$ ) for a one-unit increase of current cognition in $\mathrm{AD}$ subjects after 0,2 , and 4 years in the cohort, respectively.

The size of these temporal associations can be compared with others. For instance, for the same current cognitive level, and the same other confounding factors, the annual change of functional limitations was reduced by $1.105(95 \% \mathrm{CI}=0.267,1.943, p=0.010), 0.643(95 \% \mathrm{CI}$ $=0.038,1.247, p=0.037)$, and $0.877(95 \% \mathrm{CI}=0.269$, $1.484, p=0.005)$ for a one-unit increase of current functional limitation in $\mathrm{CN}, \mathrm{MCI}$, and $\mathrm{AD}$, respectively. The annual increase in functional limitations was also less pronounced for low educated subjects compared to higher educated subjects with a constant mean difference of $-0.471(95 \% \mathrm{CI}=-0.828,-0.114, P=0.010)$.

Adjusted for current cognitive and functional levels and other confounding factors, there was no residual association with an annual change of cognition or limitation for gender, APOE $\varepsilon 4$, and age except for the oldest (> 88.3 years old) who had a higher increase of functional dependency than younger participants. There was also a residual association of clinical status with functional change, $\mathrm{AD}$ individuals having a much higher functional annual change $(\mathrm{MD}=2.166,95 \% \mathrm{CI}=0.784,3.549, P<$ 0.002) than $\mathrm{CN}$ and $\mathrm{MCI}$.

\section{Discussion}

Leveraging longitudinal cohort data and exploiting a dynamic statistical model dedicated to the evaluation of temporal associations, this work allows understanding the cognitive and functional trajectories over time along the $\mathrm{AD}$ continuum, from normal cognitive aging to $\mathrm{MCI}$ and $\mathrm{AD}$, and assesses the temporal relationships between cognitive and functional dimensions. Our study showed that better cognitive abilities were associated with a lower subsequent decline of the functional level among $\mathrm{CN}, \mathrm{MCI}$, and $\mathrm{AD}$, but with no reciprocity whatever the clinical stage. We adjusted on main confounders identified in cognitive aging studies but cannot exclude residual confounding in these relationships.

Our results are consistent with part of the few studies that explored the potential reciprocal causal-effect between cognitive decline and functional impairment and showed that in MCI subjects or non-demented community-dwelling older persons the cognitive impairment preceded and predicted subsequent functional

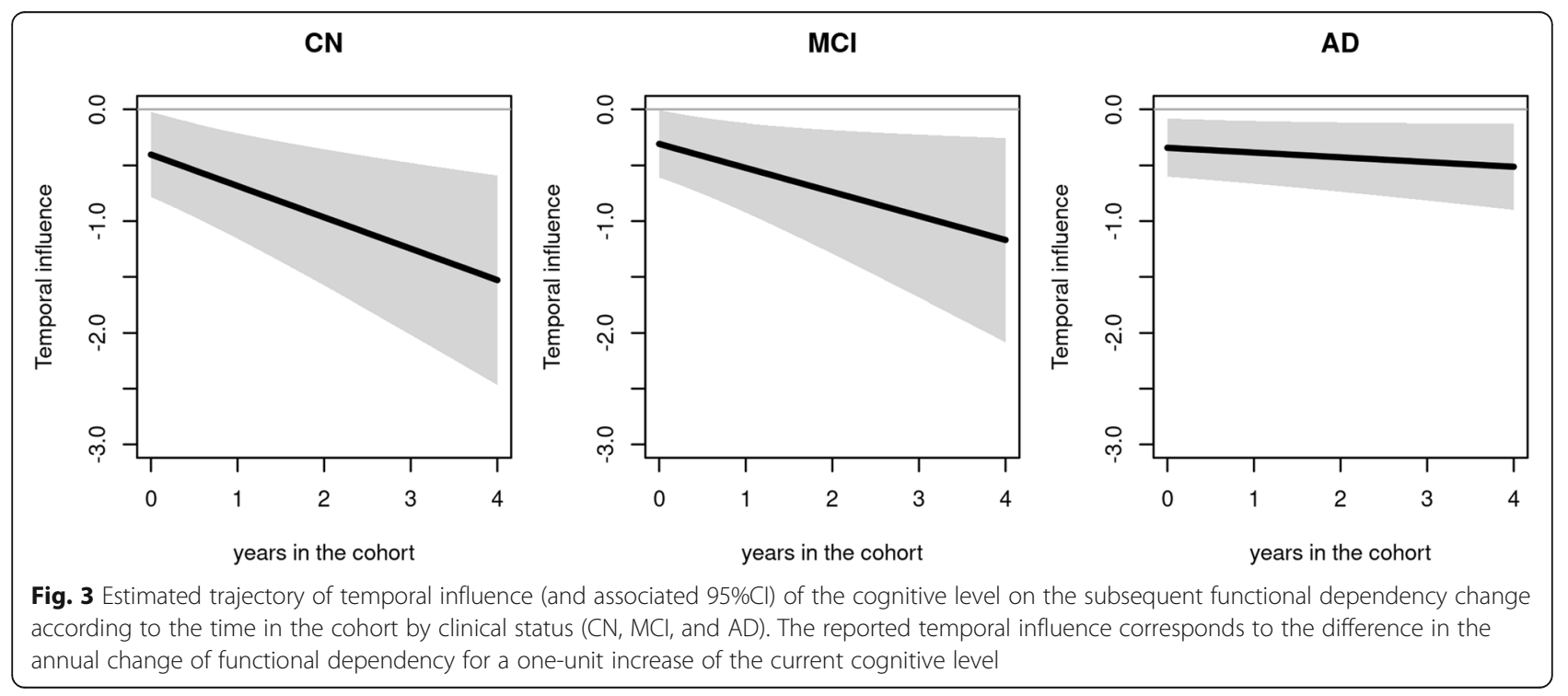


decline but functional impairment did not predict cognitive decline [7-9, 33, 34]. Although Zahodne et al. [10] also concluded to a main causal effect of the cognitive impairment on the functional decline, they reported more mixed findings with a causal effect of the functional decline on the cognitive impairment also observed at a few times in non-demented elders and prevalent $\mathrm{AD}$ but not in incident AD. Several other studies have not formally explored the dynamic bi-directional association, but rather described the trajectories of cognitive and functional abilities and compared the shape of the declines in the pre-dementia phase. They identified that the decline in cognitive performances (observed first in measures of semantic memory and conceptual formation, and then in more global cognitive functioning) preceded the increase in dependency in IADL and in BADL $[1,35]$.

From a methodological point of view, differences in the literature results could first be attributable to heterogeneity in the scales used to assess cognitive and functional dimensions, some functional scales including for instance a social dimension. Second, previous works used ARCL models which focus on (i) determinants of inter-individual differences over time rather than determinants of intra-individual changes $[12,13]$ and (ii) differences between observed visits in the study rather than differences in continuous [12-14] or finely discretized [17] time which are yet necessary for causal interpretations. The use of ARCL models makes previous results strongly dependent on the visit schedule, possibly too sparse for causal interpretation, and different from one study to the other so that comparisons are challenging. It also assumes that processes do not substantially change over time at the individual level which is very unlikely. In our work, we circumvented these limits by exploring associations with the subsequent individual rate of change of each dimension and retrieving association over a 3-month period which is unrelated to the visit schedule and very small compared to the $\mathrm{AD}$ process timescale. By relying on the mixed model theory, the method naturally handled intermittent and monotonic missing data under the missing at random mechanism [36]. We also considered that the temporal relationships may evolve between $\mathrm{CN}, \mathrm{MCI}$, and $\mathrm{AD}$, and over time within each group, thus allowing the identification of specific time windows where the cognitive/ functional dimensions could have a more important influence on the evolution of the other. We underlined that the cognitive latent dimension influenced the functional change at each stage of the disease and at each time window of interest. However, the influence of high cognitive abilities in maintaining the functional abilities increased over time, particularly in cognitively normal and MCI subjects.
A major strength of this work is the repeated longitudinal data collected in the COGICARE study. Exploring subtle changes in the dynamic of cognitive and functional dimensions was made possible by the regular follow-up of elders along the disease process. In this study, the MCI and AD groups were precisely defined. Subjects with AD were identified through an active screening and confirmed by an independent experts committee. The potential of a misclassification bias is thus minimized. The threshold used to identify MCI has also been shown to discriminate MCI who will develop AD from MCI non-converters [21]. Targeting these subjects offered the opportunity to better characterize the prodromal period of $\mathrm{AD}$. When exploring temporal relationships, the number of repeated measures is also a critical issue. The median number of visits per subject in our study was 5 in all groups both for the cognitive and functional dimensions. It is particularly valuable for $\mathrm{AD}$ as the disease is often closely associated with attrition that can potentially introduce bias in the results and lower the possibility to assess the dynamic of processes. Finally, the cognitive dimension was defined from an extensive battery of cognitive tests including global functioning, visuo-spatial memory, verbal fluency, and executive functioning, domains particularly central in cerebral aging. The definition of a general latent cognitive factor using these specific domains had been previously validated by the authors [37].

\section{Limitations}

This study has some limitations. First, some psychometric tests (BVRT for $\mathrm{CN}$ and TMT-B for all groups) were only assessed during the $\mathrm{BC}$ interviews. Considering TMT-B substantially reduced the size of the sample (112 participants did not have any TMT-B evaluation). However, it was critical that the cognitive dimension included an assessment of executive functioning given the robust relationship between instrumental activities of daily living and tests of executive function repeatedly identified in the literature (e.g., [38]).

Second, at COGICARE visits, MMSE and IST scores resulted from telephonic interviews among controls and from face-to-face interviews in $\mathrm{MCI}$ and $\mathrm{AD}$ subjects. However, it has been shown that telephonic version of MMSE provides reliable results [39]. In addition, the shape of the latent cognitive process trajectories over time among controls seems coherent with previous studies $[1,40]$. Functional dependency was assessed through a summary score of 4 instrumental activities of daily living and 5 basic activities of daily living following previous works that showed a continuum of degradation in these items $[29,30]$. However, by focusing on (instrumental) activities of daily living, we might have missed very early changes in functional dependency. Finally, we 
considered that data were missing at random and we did not take into account the possible changes of status over time. Yet, by the end of the follow-up, 26 of the 123 MCI had become AD, and 24/8 of the 102 controls had become MCI/AD. Therefore results must be interpreted for groups of subjects initially healthy, MCI or AD.

\section{Conclusion}

The approach we used provides valuable information on the dynamic co-evolution of the cognitive and function dimensions along the $\mathrm{AD}$ continuum. This work supports the hypothesis that cognitive performances contribute to maintain functional abilities whether subjects are cognitively normal or in the pathological process of cognitive decline. As stated in a recent FDA report [41], such a result is an essential argument to reinforce persuasiveness of the clinical trials identifying treatment effect on cognitive functioning. We highlighted that the benefit of cognitive performances in maintaining functional abilities increased over time when subjects were cognitively normal or at the beginning of the pathological process $(\mathrm{MCI})$ but not at later stages $(\mathrm{AD})$ when the severity of the disease is probably so high that function cannot be maintained. In the absence of a cure for $\mathrm{AD}$, a pivotal challenge is to maintain a good quality of life for future $\mathrm{AD}$ as long as possible without overwhelming functional abilities. Identifying subjects with significant cognitive impairments as early as possible is consequently crucial so that they can benefit from preventive measures before the appearance of AD clinical signs.

\section{Supplementary Information}

The online version contains supplementary material available at https://doi. org/10.1186/s13195-021-00887-4

\section{Additional file 1.}

\section{Acknowledgements}

Computer time was provided by the computing facilities MCIA (Mésocentre de Calcul Intensif Aquitain) at the Université de Bordeaux and the Université de Pau et des Pays de l'Adour.

\section{Authors' contributions}

All authors contributed to the study conception and design. Acquisition of the data was performed by Catherine Helmer and Claudine Berr. Statistical analyses were performed by Sophie Carles, Bachirou Taddé and Cécile Proust-Lima. All the authors contributed to the interpretation of the results. The first draft of the manuscript was written by Sophie Carles and Cécile Proust-Lima, and all authors commented on previous versions of the manuscript. All authors read and approved the final manuscript.

\section{Funding}

This study was funded by the French National Research Agency [grant ANR15-CE37-0002 for the SMALA project, grant ANR-07-LVIE-003 for the COGICARE project].

\section{Availability of data and materials}

Anonymized data will be shared by reasonable request to the $3 \mathrm{C}$ scientific committee. Scripts for replicating the analyses can be sent on demand.

\section{Declarations}

Ethics approval and consent to participate

The study protocols of the $3 \mathrm{C}$ and COGICARE studies used in this work were approved by the Ethics Committee of the University Hospital of Bicêtre and Sud-Méditerranée III (France) and written informed consent was obtained for each participant.

\section{Consent for publication}

Not applicable

\section{Competing interests}

No conflict of interest or competing interests.

\section{Author details}

${ }^{1}$ Institute for Neurosciences of Montpellier INM, Univ. Montpellier, INSERM, F-34091 Montpellier, France. ${ }^{2}$ Univ. Bordeaux, INSERM, BPH, U1219, F-33000 Bordeaux, France.

Received: 13 November 2020 Accepted: 9 August 2021

Published online: 03 September 2021

\section{References}

1. Amieva H, Le Goff M, Millet X, Orgogozo JM, Pérès K, Barberger-Gateau P, et al. Prodromal Alzheimer's disease: successive emergence of the clinical symptoms. Ann Neurol. 2008;64(5):492-8. https://doi.org/10.1002/ana.21509.

2. Braak H, Thal DR, Ghebremedhin E, Del Tredici K. Stages of the pathologic process in Alzheimer disease: age categories from 1 to 100 years. J Neuropathol Exp Neurol. 2011;70(11):960-9. https://doi.org/10.1097/NEN. Ob013e318232a379.

3. Dartigues JF, Gagnon M, Barberger-Gateau P, Letenneur L, Commenges D, Sauvel C, et al. The Paquid epidemiological program on brain ageing. Neuroepidemiology. 1992;11(Suppl 1):14-8. https:/doi.org/10.1159/000110955.

4. American Psychiatric Association. Diagnostic and Statistical Manual of Mental Disorders [Internet]. Fifth Edition. Arlington (VA): American Psychiatric Association; 2013. Available from: https://psychiatryonline.org/ doi/book/10.1176/appi.books.9780890425596

5. Knopman DS. Alzheimer's Disease and Other Dementias. Goldman's Cecil Medicine: Twenty Fourth Edition [Internet]. Elsevier Inc.; 2011 [cited 2020 Sep 17];2274-83. Available from: https://mayoclinic.pure.elsevier.com/en/ publications/alzheimers-disease-and-other-dementias-3

6. Liu-Seifert H, Siemers E, Selzler K, Sundell K, Aisen P, Cummings J, et al. Correlation between Cognition and Function across the Spectrum of Alzheimer's Disease. J Prev Alzheimers Dis. 2016;3(3):138-44. https://doi. org/10.14283/jpad.2016.99.

7. Liu-Seifert H, Siemers E, Sundell K, Mynderse M, Cummings J, Mohs R, Aisen P Analysis of the Relationship of Cognitive Impairment and Functional Impairment in Mild Alzheimer's Disease in EXPEDITION 3. J Prev Alzheimers Dis [Internet]. 2018 [cited 2020 Sep 17];5:184-7. Available from: https://doi. org/10.14283/jpad.2018.22, 1, 4

8. Liu-Seifert H, Siemers E, Sundell K, Price K, Han B, Selzler K, et al. Cognitive and functional decline and their relationship in patients with mild Alzheimer's dementia. J Alzheimers Dis. 2015;43(3):949-55. https://doi.org/1 0.3233/JAD-140792.

9. Liu-Seifert H, Siemers E, Price K, Han B, Selzler KJ, Henley D, et al. Cognitive Impairment Precedes and Predicts Functional Impairment in Mild Alzheimer's Disease. J Alzheimers Dis. 2015;47(1):205-14. https://doi.org/1 0.3233/JAD-142508.

10. Zahodne LB, Manly JJ, Mackay-Brandt A, Stern Y. Cognitive declines precede and predict functional declines in aging and Alzheimer's disease. PLOS ONE. 2013;8(9):e73645. https://doi.org/10.1371/journal.pone.0073645.

11. Reppermund S, Brodaty H, Crawford JD, Kochan NA, Draper B, Slavin MJ, et al. Impairment in instrumental activities of daily living with high cognitive demand is an early marker of mild cognitive impairment: the Sydney memory and ageing study. Psychological Medicine. 2013;43(11):2437-45. https://doi.org/10.1017/S003329171200308X.

12. Selig JP, Preacher KJ. Mediation Models for Longitudinal Data in Developmental Research. Research in Human Development [Internet]. Routledge; 2009 [cited 2020 Sep 17];6:144-64. Available from: https://doi. org/10.1080/15427600902911247 
13. Voelkle MC, Gische C, Driver CC, Lindenberger U. The Role of Time in the Quest for Understanding Psychological Mechanisms. Multivariate Behav Res. 2018;53(6):782-805. https://doi.org/10.1080/00273171.2018.1496813.

14. Aalen OO, Røysland K, Gran JM, Kouyos R, Lange T. Can we believe the DAGs? A comment on the relationship between causal DAGs and mechanisms. Stat Methods Med Res. 2016;25(5):2294-314. https://doi.org/1 $0.1177 / 0962280213520436$

15. Proust-Lima C, Amieva H, Dartigues J-F, Jacqmin-Gadda H. Sensitivity of four psychometric tests to measure cognitive changes in brain agingpopulation-based studies. Am J Epidemiol. 2007;165(3):344-50. https://doi. org/10.1093/aje/kwk017.

16. Proust-Lima C, Dartigues JF, Jacqmin-Gadda H. Misuse of the linear mixed model when evaluating risk factors of cognitive decline. Am J Epidemiol. 2011;174(9):1077-88. https://doi.org/10.1093/aje/kwr243.

17. Taddé BO, Jacqmin-Gadda H, Dartigues J-F, Commenges D, Proust-Lima C. Dynamic modeling of multivariate dimensions and their temporal relationships using latent processes: Application to Alzheimer's disease. Biometrics. 2020;76(3):886-99. https://doi.org/10.1111/biom.13168.

18. 3C Study Group. Vascular factors and risk of dementia: design of the ThreeCity Study and baseline characteristics of the study population. Neuroepidemiology. 2003:22:316-25.

19. American Psychiatric Association. Diagnostic and Statistical Manual of Mental Disorders. 4th ed. Washington, DC: American Psychiatric Press; 1994.

20. McKhann G, Drachman D, Folstein M, Katzman R, Price D, Stadlan EM. Clinical diagnosis of Alzheimer's disease: report of the NINCDS-ADRDA Work Group under the auspices of Department of Health and Human Services Task Force on Alzheimer's Disease. Neurology. 1984;34(7):939-44. https://doi. org/10.1212/WNL.34.7.939.

21. Sarazin M, Berr C, De Rotrou J, Fabrigoule C, Pasquier F, Legrain S, et al. Amnestic syndrome of the medial temporal type identifies prodromal AD: a longitudinal study. Neurology. 2007;69(19):1859-67. https://doi.org/10.1212/ 01.wnl.0000279336.36610.f7.

22. Grober E, Sanders AE, Hall C, Lipton RB. Free and cued selective reminding identifies very mild dementia in primary care. Alzheimer Dis Assoc Disord. 2010;24(3):284-90. https://doi.org/10.1097/WAD.0b013e3181cfc78b.

23. Lawton MP, Brody EM. Assessment of older people: self-maintaining and instrumental activities of daily living. Gerontologist. 1969;9(3 Part 1):179-86. https://doi.org/10.1093/geront/9.3_Part_1.179.

24. Folstein MF, Folstein SE, McHugh PR. "Mini-mental state". A practical method for grading the cognitive state of patients for the clinician. J Psychiatr Res. 1975;12(3): 189-98. https:/doi.org/10.1016/0022-3956(75)90026-6.

25. Isaacs B, Kennie AT. The Set test as an aid to the detection of dementia in old people. Br J Psychiatry. 1973;123(575):467-70. https://doi.org/10.1192/ bjp.123.4.467.

26. Benton AL. Test de rétention visuelle (2e éd.). Paris: les Editions du Centre de Psychologie Appliquée; 1965.

27. Reitan RM. Validity of the Trail Making Test as an Indicator of Organic Brain Damage Percept Mot Skills [Internet]. SAGE Publications Inc; 1958 [cited 2021 Mar 19];8:271-6. Available from: https://doi.org/10.2466/pms.1958.8.3.271

28. Katz S, Ford AB, Moskowitz RW, Jackson BA, Jaffe MW. Studies of Illness in the Aged: The Index of ADL: A Standardized Measure of Biological and Psychosocial Function. JAMA [Internet]. American Medical Association; 1963 [cited 2020 Oct 15];185:914-9. Available from: https://jamanetwork.com/ journals/jama/fullarticle/666768

29. Barberger-Gateau P, Rainville C, Letenneur L, Dartigues JF. A hierarchical model of domains of disablement in the elderly: a longitudinal approach. Disabil Rehabil. 2000;22(7):308-17. https://doi.org/10.1080/096382800296665.

30. Edjolo A, Proust-Lima C, Delva F, Dartigues J-F, Pérès K. Natural History of Dependency in The Elderly. A 24-Year Population-Based Study using a Longitudinal Item Response Theory Model. American Journal of Epidemiology. 2015; accepted.

31. Proust-Lima C, Amieva H, Jacqmin-Gadda H. Analysis of multivariate mixed longitudinal data: a flexible latent process approach. Br J Math Stat Psychol. 2013;66(3):470-87. https://doi.org/10.1111/bmsp.12000.

32. Laird NM, Ware JH. Random-effects models for longitudinal data. Biometrics. 1982;38(4):963-74. https://doi.org/10.2307/2529876

33. Njegovan V, Hing MM, Mitchell SL, Molnar FJ. The hierarchy of functional loss associated with cognitive decline in older persons. J Gerontol A Biol Sci Med Sci. 2001;56(10):M638-43. https://doi.org/10.1093/gerona/56.10.M638.

34. Ishizaki T, Yoshida H, Suzuki T, Watanabe S, Niino N, Ihara $K$, et al. Effects of cognitive function on functional decline among community-dwelling non- disabled older Japanese. Arch Gerontol Geriatr. 2006:42(1):47-58. https://doi. org/10.1016/j.archger.2005.06.001.

35. Verlinden VJA, van der Geest JN, de Bruijn RFAG, Hofman A, Koudstaal PJ, Ikram MA. Trajectories of decline in cognition and daily functioning in preclinical dementia. Alzheimer's \& Dementia. 2016;12(2):144-53. https://doi. org/10.1016/j.jalz.2015.08.001.

36. Little R, Rubin DB. Statistical analysis with missing data. John Wiley \& Sons; 2019.

37. Proust-Lima C, Amieva H, Letenneur L, Orgogozo JM, Jacqmin-Gadda H, Dartigues JF. Gender and education impact on brain aging: a general cognitive factor approach. Psychol Aging. 2008;23(3):608-20. https://doi. org/10.1037/a0012838.

38. Szlyk JP, Myers L, Zhang Y, Wetzel L, Shapiro R. Development and assessment of a neuropsychological battery to aid in predicting driving performance. J Rehabil Res Dev. 2002;39(4):483-96.

39. Newkirk LA, Kim JM, Thompson JM, Tinklenberg JR, Yesavage JA, Taylor JL. Validation of a 26-point telephone version of the Mini-Mental State Examination. Journal of Geriatric Psychiatry and Neurology. 2004;17(2):81-7. https://doi.org/10.1177/0891988704264534.

40. Amieva H, Jacqmin-Gadda H, Orgogozo J-M, Le Carret N, Helmer C, Letenneur $\mathrm{L}$, et al. The 9 year cognitive decline before dementia of the Alzheimer type: a prospective population-based study. Brain. 2005;128(5): 1093-101. https://doi.org/10.1093/brain/awh451.

41. Center for Drug Evaluation and Research. Alzheimer's Disease: Developing Drugs for Treatment Guidance for Industy [Internet]. Food and Drug Administration; 2018. Report No.: FDA-2013-D-0077. Available from: https:// www.fda.gov/regulatory-information/search-fda-guidance-documents/a Izheimers-disease-developing-drugs-treatment-guidance-industy

\section{Publisher's Note}

Springer Nature remains neutral with regard to jurisdictional claims in published maps and institutional affiliations.
Ready to submit your research? Choose BMC and benefit from:

- fast, convenient online submission

- thorough peer review by experienced researchers in your field

- rapid publication on acceptance

- support for research data, including large and complex data types

- gold Open Access which fosters wider collaboration and increased citations

- maximum visibility for your research: over $100 \mathrm{M}$ website views per year

At $\mathrm{BMC}$, research is always in progress.

Learn more biomedcentral.com/submissions 